\title{
Myocardial infarct size and mortality in diabetic patients
}

\author{
D J GWILT, M PETRI, P W LEWIS, M NATTRASS, B L PENTECOST \\ From the General Hospital, Steelhouse Lane, Birmingham
}

SUMMARY The mortality rate from myocardial infarction is disproportionately high in diabetic patients. One explanation for this may be that diabetic patients incur more extensive myocardial necrosis. This possibility was examined in a three part study. Firstly, peak serum aspartate aminotransferase concentrations of all diabetic and non-diabetic patients admitted with myocardial infarction over a 16 year period were compared retrospectively. Secondly, peak aspartate aminotransferase concentrations in a series of diabetic patients and controls matched by age and sex were examined retrospectively. Thirdly, creatine kinase $\mathrm{MB}$ release and electrocardiographic measures of infarct size were investigated prospectively in a case/control study. Although cardiac failure and death were more common in the diabetic groups, there were no significant differences in estimates of infarct size between diabetic and non-diabetic patients in any of the studies.

Therefore, the high case fatality rate amongst diabetic patients is not caused by increased myocardial damage. Presumably survival is prejudiced by factors operating before the infarction.

Diabetic patients are at increased risk of death from myocardial infarction. ${ }^{12}$ Not only is there a higher incidence of infarction ${ }^{3}$ but the case fatality rate is about 1.5 to 2.0 times higher than it is in nondiabetic patients. ${ }^{45}$

In general, the major determinant of mortality once the patient has reached hospital is the degree of myocardial necrosis, ${ }^{67}$ and, therefore, one explanation of the diabetic death rate could be more extensive infarction. There are theoretical reasons why this might be so-diabetic patients may have more extensive coronary disease ${ }^{8}$; local tissue oxygenation may be disproportionately impaired by a combination of basement membrane thickening, ${ }^{9}$ decreased deformability of red cells, ${ }^{10}$ increased viscosity, ${ }^{11}$ and hypercoagulability of blood ${ }^{12}$; also a relative insufficiency of insulin ${ }^{13}$ is likely to lead to impairment of glycolysis (the only source of high energy phosphate in ischaemia ${ }^{14}$ ) and to an undue increase in non-esterified fatty acids which may further increase infarct size. ${ }^{15}$

Therefore, in trying to unravel the cause of the high mortality from myocardial infarction in diabetic patients it is important to determine whether

Requests for reprints to Dr D J Gwilt, General Hospital, Standing Way, Eaglestone, Milton Keynes MK6 5LD.

Accepted for publication 12 July 1985 infarct size is greater in these patients. We have evaluated infarct size in three separate surveys in an attempt to explore the possible causes of increased mortality from myocardial infarction in diabetic patients.

\section{Patients and methods}

We conducted three separate surveys.

SURVEY 1967-83

All patients known before admission to be diabetic who were admitted to the coronary care unit between January 1967 and December 1983 with myocardial infarction were studied retrospectively. Myocardial infarction was diagnosed by the presence of two out of three of the following criteria: ischaemic pain lasting more than $\mathbf{3 0}$ minutes; development of new $Q$ waves of longer than $30 \mathrm{~ms}$ duration; and a rise in serum aspartate aminotransferase concentrations to greater than twice the upper limit of normal.

For convenience only half of the non-diabetic patients were evaluated. Four periods of two years (1967-68, 1972-73, 1977-78, and August 1981 to December 1983) were selected and all non-diabetic patients admitted to the coronary care unit with myocardial infarction during these years were identified. Patients in whom diabetes was diagnosed 
only after admission were excluded from the study and patients who were re-admitted were treated statistically as a second patient. Peak serum aspartate aminotransferase and hospital mortality were determined from hospital records. The assay for aspartate aminotransferase has not altered over the past 16 years.

\section{SURVEY 1979-83}

In a second retrospective study all diabetic patients admitted from January 1979 to December 1983 with myocardial infarction were matched by age $( \pm 5$ years) and sex with the next appropriate nondiabetic patient who was admitted. For these patients peak aspartate aminotransferase, hospital course, and mortality were determined. To be sure that peak aspartate aminotransferase concentration had been measured we excluded patients admitted

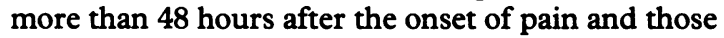
who died less than 24 hours after the onset of pain.

\section{SURVEY 1982-84}

In a prospective study, all diabetic patients admitted from July 1982 to May 1984 suspected of having a myocardial infarction were paired with the next non-diabetic patient, matched by age ( \pm 5 years), sex, and presence or absence of a previous history of myocardial infarction (irrespective of the number of infarcts). Patients were excluded if the onset of pain occurred more than 12 hours before admission to the coronary care unit. Blood was sampled on admission and every eight hours for $\mathbf{7 2}$ hours. All patients suspected of having an infarction were studied, but patients were later excluded if they did not meet the diagnostic criteria. Results from those who died within 72 hours (before the blood sampling was completed) were also excluded.

All patients had electrocardiographic monitoring for 24 hours with access to immediate write-out. We noted arrhythmias that were unlikely to be overlooked: complete heart block, ventricular fibrillation and atrial fibrillation. Left ventricular failure (diagnosed on the basis of the following - a third heart sound, widespread crepitations, or a chest $x$ ray film showing pulmonary oedema) and cardiogenic shock (hypotension, poor perfusion, and low urine output) were also noted.

\section{Analysis of creatine kinase $M B$}

Plasma concentrations of creatine kinase MB isoenzyme activity were determined by an immunoinhibition method (kit no 300691; Boehringer Mannheim) at $340 \mathrm{~nm}$ and expressed as $\mathrm{U} / 1$ at $37^{\circ} \mathrm{C}$. Plasma specimens treated with edetic acid were used and a plasma blank correction was determined and applied to each specimen.
Calculation of infarct size

The mean plasma concentration of creatine kinase MB in a series of 30 hospital patients without myocardial infarction was $20 \mathrm{U} / 1$ and this was subtracted from all values of creatine kinase MB. The disappearance coefficient $(\mathrm{kd})$ was calculated by application of exponential regression analysis to the descending portions of the creatine kinase MB time curve (using a Super-Brain Computer and Stats-pak programme). The infarct size was calculated by the formulas of Shell et $\mathrm{al}^{16}$ as modified by Norris et al. ${ }^{17}$ For small infarcts, where there is a degree of inaccuracy in the determination of kd, we made the arbitrary rule that if the correlation coefficient of the regression line was less than 0.95 that value of $\mathrm{kd}$ was rejected and the mean of the pooled values of $\mathrm{kd}$ was used.

\section{Comparison of creatine kinase $M B$ kinetics}

We analysed the release of creatine kinase $M B$ in the diabetic and non-diabetic patients by comparing the disappearance coefficient and the time to peak creatine kinase $M B$ in the two groups. In addition, the creatine kinase $\mathrm{MB}$ released was found for each patient at $6,12,18$, and 24 hours by extrapolation of each curve and this was then expressed as a percentage of total creatine kinase $\mathrm{MB}$ released, these percentage values were averaged for the two groups so that accumulation curves for diabetic or nondiabetic patients could be compared.

\section{Electrocardiographic analysis}

To support the enzyme data we also used two simple electrocardiographic analyses of infarct size-QRS scoring ${ }^{18}$ and the presence or absence of reciprocal ST depression. ${ }^{19}$ For the QRS score the 12 lead electrocardiogram was recorded daily at a standard speed $(25 \mathrm{~mm} / \mathrm{s})$ and sensitivity $(1 \mathrm{mV} / \mathrm{cm})$; the last available electrocardiogram up to and including the seventh day after infarction was analysed for this purpose. Patients with previous infarction, left ventricular hypertrophy, or conduction abnormalities were excluded from the QRS scoring study. Reciprocal depression was defined as ST depression of 1 $\mathrm{mm}$ or more in at least two leads remote from the infarct site and was scored as being present if seen on any electrocardiogram. Patients with electrocardiographic defects were also excluded from this study.

\section{Study size}

From our initial study of aspartate aminotransferase and mortality in non-diabetic patients, it was evident that if the excess mortality in our hospital were solely the result of increased infarct size, then the diabetic population would be expected to have $50 \%$ more myocardial necrosis than the non-diabetic pa- 
tients. Using this figure, a power of $90 \%$, the standard deviation of a pilot study on creatine kinase $\mathrm{MB}$ sizing of infarcts, and looking for significance at the $5 \%$ level we calculated that data from 25 matched pairs were needed to exclude a positive result ${ }^{20}$ (in the end we recruited 38 pairs).

\section{STATISTICS}

Groups were compared by Student's $t$ tests and by $\chi^{2}$ tests with the Yates's correction as appropriate.

\section{Results}

\section{RETROSPECTIVE STUDY 1967-83}

From 1967 to 1983, the 456 diabetic patients admitted with myocardial infarction had a hospital mortality of $33.6 \%$, in contrast to the $18.3 \%$ mortality $(p<0.001)$ in 1951 non-diabetic patients admitted over the four two year periods of the study. Serum aspartate aminotransferase levels and mortality data were available for $1516(78 \%)$ of the non-diabetic patients and $328(72 \%)$ of the diabetic group. The distributions of serum aspartate aminotransferase concentrations are almost identical in the two groups (Fig. 1). Mortality increased with peak aspartate aminotransferase in both groups (Fig. 2), but at any aspartate aminotransferase concentration mortality in the diabetics exceeded that in the non-diabetics $(p<0.001)$, suggesting that the excess mortality is not solely due to infarct size.

\section{CASE MATCHED STUDY 1979-83}

Over the period of this study 167 diabetic patients were admitted with infarction; 50 died (30\%). During the same period $228(18.6 \%, p<0.001)$ of 1224 non-diabetic patients died. We studied 120 pairs of

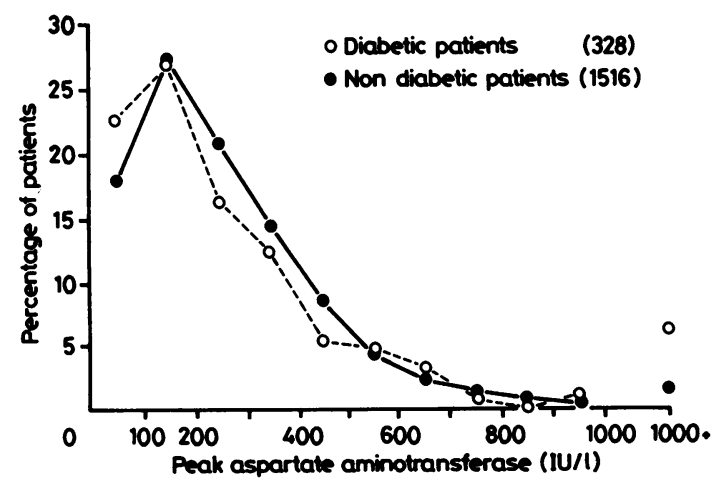

Fig. 1 Distribution of peak serum aspartate aminotransferase concentrations in retrospective analysis of 1967-83 data from diabetic and non-diabetic patients with myocardial infarction.

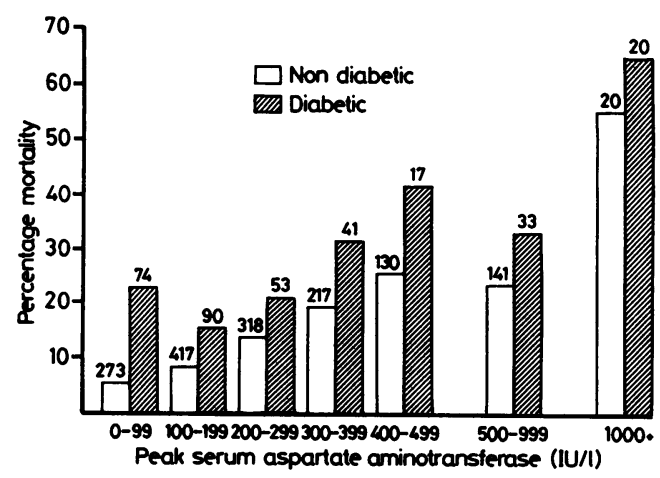

Fig. 2 Mortality of peak serum aspartate aminotransferase concentrations in 1967-83 retrospective analysis of diabetic and non-diabetic patients with myocardial infarction. Numbers above the bars are the number of patients.

patients from these groups; the two age and sex matched groups were similar (Table 1) for prevalence of hypertension, previous myocardial infarction, and renal dysfunction (as judged by admission creatinine concentrations). Arrhythmias were not more common in the diabetic group but $\overrightarrow{0}$ haemodynamic problems (cardiogenic shock plus ô left ventricular failure) were (49\% compared with $28 \%$ in the non-diabetics, $p<0.01$ ), and Killip and Kimball grading was also significantly different in the two groups. ${ }^{21}$ In the diabetic group there was a statistically significant increase in the frequency of $\frac{O}{\mathbb{N}}$ cardiogenic shock and an increase (but not a significant one) in left ventricular failure. To test for bias in our clinical haemodynamic assessment we looked at the death rate for each heart disease category. For cardiac failure, $27 \%$ of the diabetic and $23 \%$ of the non-diabetic patients died and for cardiogenic shock $94 \%$ of diabetic and $100 \%$ of non- $\frac{\varrho}{7}$ diabetics died. These values are so similar that diagnostic bias seems unlikely. The death rate in the diabetic group was higher than that in the non- $\delta$ diabetic group $(23 \%$ vs $9 \%, \mathrm{p}<0.01)$; the overall death rate was lower than that in the 1967-83 survey을 because of the exclusion criteria used. But despite $>$ the higher frequency of haemodynamic failure and을. death in the diabetics serum aspartate amino- N transferase concentrations were almost identical in the two groups (mean diabetic concentration 366 $\mathrm{U} / 1$, mean non-diabetic $357 \mathrm{U} / \mathrm{l}$, Fig. 3). This ac- $\mathrm{E}$ cords with the conclusions of the previous study that excess mortality in diabetic patients is not simplyo due to infarct size.

PROSPECTIVE CREATINE KINASE MB CASE CONTROL STUDY (1982-84)

Sixty five diabetics were admitted to hospital in this? study period and 24 were excluded (10 died befor $\mathscr{B}_{2}$ 
Table 1 Survey $1979-83$

\begin{tabular}{|c|c|c|c|}
\hline Patients & Diabetic & Non-diabetic & Significance \\
\hline $\begin{array}{l}\text { No } \\
\text { Age in years } \\
\text { Sex } \\
\text { Previous history }\end{array}$ & $\begin{array}{l}120 \\
62 \cdot 4(9 \cdot 2) \\
91 \text { male }\end{array}$ & $\begin{array}{l}120 \\
62 \cdot 2(9 \cdot 0) \\
91 \text { male }\end{array}$ & $\begin{array}{l}\text { NS } \\
\text { NS }\end{array}$ \\
\hline $\begin{array}{l}\text { Hypertension } \\
\text { Myocardial infarction } \\
\text { Serum creatinine }>125 \mu \mathrm{mol} / 1 \\
\text { Serum creatinine }>300 \mu \mathrm{mol} / 1 \\
\text { Complications }\end{array}$ & $\begin{array}{l}15(13 \%) \\
27(23 \%) \\
28(25 \%) \\
1(1 \%)\end{array}$ & $\begin{array}{l}19(16 \%) \\
15(13 \%) \\
18(17 \%) \\
2(2 \%)\end{array}$ & $\begin{array}{l}\text { NS } \\
\text { NS } \\
\text { NS } \\
\text { NS }\end{array}$ \\
\hline $\begin{array}{l}\text { Atrial fibrillation } \\
\text { Complete heart block } \\
\text { Ventricular fibrillation } \\
\text { Left ventricular failure } \\
\text { Cardiogenic shock } \\
\text { Left ventricular failure and shock } \\
\text { Killip grades }\end{array}$ & $\begin{array}{l}19(16 \%) \\
16(13 \%) \\
10(8 \%) \\
41(34 \%) \\
18(15 \%) \\
59(49 \%)\end{array}$ & $\begin{array}{l}18(15 \%) \\
8(7 \%) \\
14(12 \%) \\
31(26 \%) \\
3(3 \%) \\
34(28 \%)\end{array}$ & $\begin{array}{l}\text { NS } \\
\text { NS } \\
\text { NS } \\
\text { NS } \\
p<0.01 \\
p<0.01\end{array}$ \\
\hline $\begin{array}{l}1 \\
2 \\
3 \\
4 \\
\text { Death }\end{array}$ & $\begin{array}{l}75 \\
23 \\
10 \\
12\end{array}$ & $\left.\begin{array}{r}98 \\
19 \\
2 \\
1\end{array}\right\}$ & $\mathrm{p}<0.001$ \\
\hline $\begin{array}{l}\text { Enzymes } \\
\text { Serum aspartate aminotransferase }(\mathrm{U} / 1)\end{array}$ & $\begin{array}{c}28(23) \\
366(322)\end{array}$ & $11(9)$ & $\begin{array}{l}p<0.01 \\
\text { NS }\end{array}$ \\
\hline
\end{tabular}

Figures are means (1 SD) and percentages. Serum creatinine was measured at admission in only 110 diabetics and 106 non-diabetic patients.

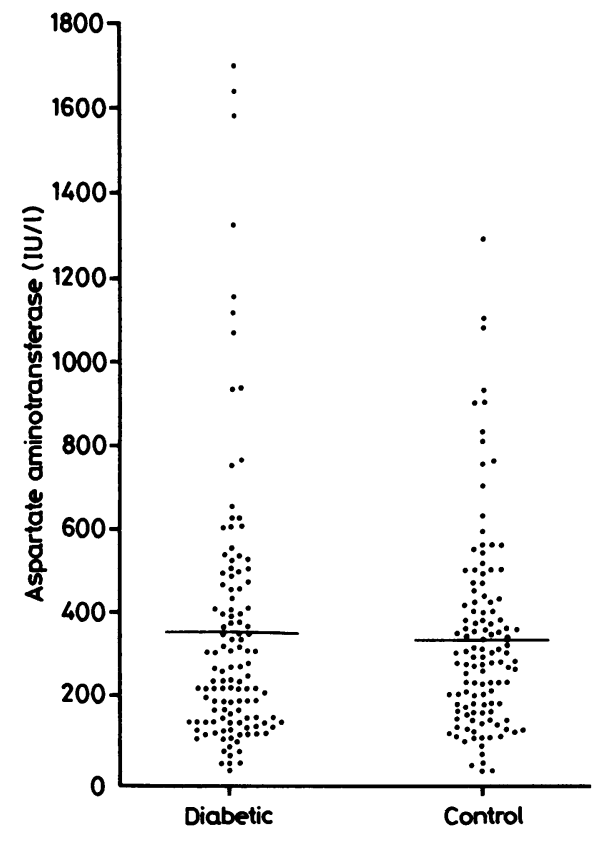

Fig. 3 Distribution of peak serum aspartate aminotransferase concentrations in $1979-83$ survey of diabetic and non-diabetic patients with myocardial infarction. Horizontal lines indicate mean values. completion of enzyme sampling, 11 arrived 12 hours or more after the onset of pain, and three were excluded at the request of their own physician). Of the 41 remaining patients two could not be matched by the end of the study and one had a reinfarction 24 hours after admission. These patients were not included.

The 38 study patients (Table 2) had been diagnosed as diabetic a mean of $11 \cdot 2$ years ago; seven were being treated by diet, 20 with oral agents, and 11 with insulin; five had some degree of retinopathy, three had proteinuria, and three had peripheral vascular disease. The histories of diabetic and non-diabetic patients were similar but fewer diabetic patients were current smokers. The frequency of arrhythmias was similar in the two groups. There was a trend to more haemodynamic complications but the numbers are too small for valid statistical analysis. Because of the exclusion criteria the death rate was low in both groups.

Whatever the method of assessment used diabetic patients did not have larger infarcts than non-diabetic patients (Table 3). The 95\% confidence limits of the sum of creatine kinase MB release are such that infarct size in diabetic patients might have exceeded by up to $33 \mathrm{U} / 1$ that in non-diabetics, but the chance that a larger excess could have been missed is less than $2.5 \%$. If the non-diabetic sample is assumed to be identical with the non-diabetic population, the maximum excess diabetic infarct size that could be missed by chance (at the $2.5 \%$ level) would be $6 \%$ of the infarct size in 
Table 2 Survey 1982-84

\begin{tabular}{|c|c|c|c|}
\hline Patients & Diabetic & Non-diabetic & Significance \\
\hline $\begin{array}{l}\text { No } \\
\text { Age in years } \\
\text { Sex }\end{array}$ & $\begin{array}{l}38 \\
60 \cdot 7(9 \cdot 4) \\
27 \text { male }\end{array}$ & $\begin{array}{l}38 \\
60 \cdot 7(9 \cdot 0) \\
27 \text { male }\end{array}$ & $\begin{array}{l}\text { NS } \\
\text { NS }\end{array}$ \\
\hline $\begin{array}{l}\text { Previous history } \\
\text { Hypertension } \\
\text { Myocardial infarction } \\
\text { Angina } \\
\text { Current smoker }\end{array}$ & $\begin{array}{r}11(29 \%) \\
10(26 \%) \\
4(11 \%) \\
9(24 \%)\end{array}$ & $\begin{array}{l}13(34 \%) \\
10(26 \%) \\
5(13 \%) \\
21(55 \%)\end{array}$ & $\begin{array}{l}\text { NS } \\
\text { NS } \\
\text { NS } \\
p<0.01\end{array}$ \\
\hline $\begin{array}{l}\text { Electrocardiogram abnormality } \\
\text { Anterior infarct } \\
\text { Inferior infarct } \\
\text { Right bundle branch block } \\
\text { Left bundle branch block }\end{array}$ & $\begin{array}{r}17 \\
19 \\
1 \\
1\end{array}$ & $\left.\begin{array}{r}15 \\
22 \\
1 \\
0\end{array}\right\}$ & NS \\
\hline $\begin{array}{l}\text { Complications } \\
\text { Atrial fibrillation } \\
\text { Complete heart block } \\
\text { Ventricular fibrillation } \\
\text { Left ventricular failure } \\
\text { Cardiogenic shock } \\
\text { Left ventricular failure and shock }\end{array}$ & $\begin{array}{c}6(16 \%) \\
3(8 \%) \\
3(8 \%) \\
17(45 \%) \\
3(8 \%) \\
20(53 \%)\end{array}$ & $\begin{array}{r}5(13 \%) \\
4(11 \%) \\
4(11 \%) \\
10(26 \%) \\
2(5 \%) \\
12(32 \%)\end{array}$ & $\begin{array}{l}\text { NS } \\
\text { NS } \\
\text { NS } \\
\text { NS } \\
\text { NS } \\
\text { NS }\end{array}$ \\
\hline $\begin{array}{l}\text { Killip } \\
1 \\
2 \\
3 \\
4 \\
\text { Death }\end{array}$ & $\begin{array}{r}31 \\
5 \\
2 \\
0\end{array}$ & $\left.\begin{array}{r}33 \\
4 \\
0 \\
1\end{array}\right\}$ & NS \\
\hline & 3 & 2 & NS \\
\hline
\end{tabular}

Figures are means (1 SD) and percentages.

Table 3 Estimation of infarct size

\begin{tabular}{|c|c|c|c|}
\hline & Diabetic & Non-diabetic & Significance \\
\hline \multicolumn{4}{|l|}{ By enzyme } \\
\hline $\begin{array}{l}\text { Peak aspartate aminotransferase (U/1) } \\
\text { Peak creatine kinase } \mathrm{MB}(\mathrm{U} / \mathbf{l}) \\
\text { Sum of creatine kinase } \mathrm{MB}(\mathrm{U} / \mathbf{l}) \\
\text { Creatine kinase } \mathrm{MB} \text { (gram equivalent) } \\
\text { Creatine kinase } \mathrm{MB}\left(\mathrm{g} / \mathrm{m}^{2}\right)\end{array}$ & $\begin{array}{l}472(402) \\
240(129) \\
414(241) \\
24 \cdot 0(14 \cdot 3) \\
13 \cdot 3(7 \cdot 9)\end{array}$ & $\begin{array}{l}421(321) \\
297(174) \\
525(382) \\
31 \cdot 7(25 \cdot 4) \\
17 \cdot 1(13 \cdot 1)\end{array}$ & $\begin{array}{l}\text { NS } \\
\text { NS } \\
\text { NS } \\
\text { NS } \\
\text { NS }\end{array}$ \\
\hline \multicolumn{4}{|l|}{ By electrocardiogram } \\
\hline $\begin{array}{l}\text { Reciprocal depression } \\
\text { QRS Score }\end{array}$ & $\begin{array}{r}22(61 \%)^{\star} \\
5 \cdot 7(3 \cdot 2)^{\star}\end{array}$ & $\begin{array}{r}21(57 \%) \dagger \\
6.9(3.5) \ddagger\end{array}$ & $\begin{array}{l}\text { NS } \\
\text { NS }\end{array}$ \\
\hline
\end{tabular}

$\star 36$ patients available for analysis. $\nmid 37$ patients available for analysis. $\ddagger 23$ patients available for analysis. NS, not significant. Figures are means (1 SD) and percentages.

Table 4 Creatine kinase MB kinetics in diabetic and non-diabetic patients with myocardial infarction

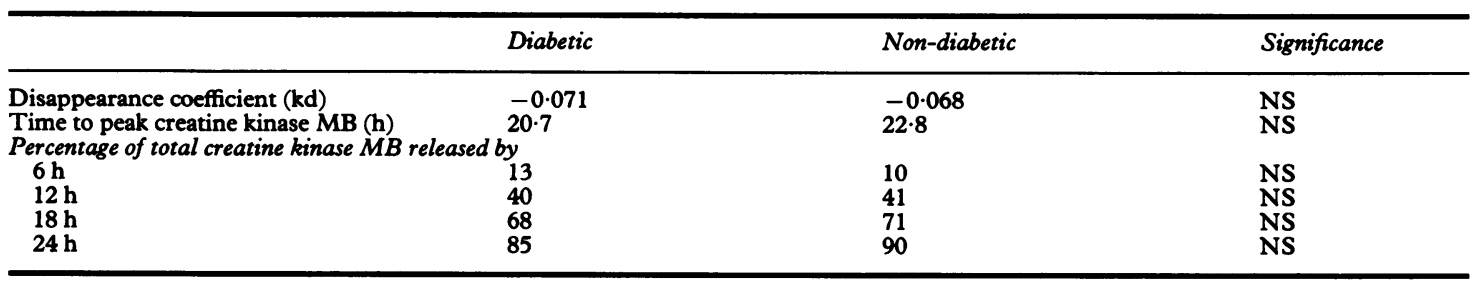

NS, not significant.

non-diabetic patients. The creatine kinase MB kinetics of diabetic and non-diabetic patients were compared (Table 4). The coefficient of disappearance (kd), time to peak creatine kinase $M B$ concentration, and the rate of release of creatine kinase $\mathrm{MB}$ expressed as a percentage of total creatine kinase $\mathrm{MB}$ release were identical in the diabetic and non-diabetic groups.

The 12 lead electrocardiographic data were examined for the two semiquantitive indices of 
infarct size-reciprocal ST depression and QRS score-and results in the diabetic and non-diabetic patients were almost identical. Therefore, it is very unlikely that diabetic patients have bigger infarcts than non-diabetic patients.

\section{Hyaluronidase}

For some years this hospital has been assessing the effect of treatment with hyaluronidase (GL enzyme) on myocardial infarction. ${ }^{22}$ Twenty three per cent of patients in the 1979-83 survey and $20 \%$ of those in the 1982-84 survey were given the drug. This is unlikely, however, to have altered our conclusions because in our experience ${ }^{22}$ and that of others ${ }^{23}$ hyaluronidase does not reduce infarct size in man as judged by cardiac enzyme release (aspartate aminotransferase or creatine kinase MB). Also it could not alter the significance of the observation that there is disparity between enzyme concentrations and mortality in the two groups; and, finally, the results are unchanged by exclusion from the analysis of all patients receiving hyaluronidase.

\section{Discussion}

The frequency of diabetes among all patients studied may have been underestimated because many were seen before haemoglobin $\mathbf{A}_{1}$ estimation had become common practice. ${ }^{24}$ Even so, approximately $2 \%$ of the apparently non-diabetic population was found to be diabetic on admission to hospital and these patients have been excluded from the study. The remainder of the non-diabetic population may have contained a further $2-3 \%$ of diabetic patients ${ }^{25}$ who could now be detected by measurement of haemoglobin $A_{1}$ but this is too small a figure significantly to influence the results.

To our knowledge no one has examined the validity of creatine kinase MB kinetics as an estimate of infarct size in the diabetic patient. This requires a parallel necropsy study which we did not perform, nor were sufficient patients available for such a study. But the disappearance coefficients, the time to peak creatine kinase $\mathrm{MB}$ concentrations, and the rates of accumulation of creatine kinase $\mathrm{MB}$ are all so similar in the two groups (Table 4) that it seems very unlikely that creatine kinase $\mathrm{MB}$ kinetics differ in diabetic patients.

Among those diabetic patients reaching hospital, the majority of deaths $(80-85 \%)$ are due to pump failure. ${ }^{26}$ In this respect they are no different from non-diabetic patients (and this study shows that arrhythmias are not more prevalent in diabetics and previous work from this hospital also indicates that ketoacidosis is a rare $(3 \%)$ complication of infarction in diabetic patients ${ }^{27}$ ). An alternative explanation of the high mortality in diabetic patients could be that they have a greater degree of myocardial necrosis which in turn might be due to more extensive coronary atheroma in diabetes; poor tissue oxygenation due to abnormalities of the microcirculation ${ }^{9-12}$; or the pronounced impairment of glycolysis ${ }^{14}$ and raised non-esterified fatty acid concentrations $^{15}$ that would be expected in the diabetic patient after infarction.

We have examined the possibility of a systematic increase in infarct size in diabetics by using three complementary sets of observations-a retrospective 16 year study of all diabetics with a relatively non-specific enzyme method of estimating infarct size, a matched series in which aspartate aminotransferase was measured, and a study which excluded some of the more seriously ill patients but which used a more specific and precise enzyme technique (creatine kinase $\mathrm{MB}$ ) reinforced by analysis of the 12 lead electrocardiogram. In none of these three sets of patients did the diabetic patients have larger infarcts than the non-diabetic ones. This accords with the results of Jaffe et al who showed that although diabetic patients have increased rates of cardiac failure after myocardial infarction, infarct size in these patients is less than that of the non-diabetic patients. ${ }^{28}$

Thus, although in theory there are mechanisms by which the diabetic might be at risk of more extensive infarction, these do not appear to be important in practice. We have also found that careful metabolic control after infarction has little effect on mortality. ${ }^{29}$ Therefore, the unknown cause of the excess death rate may well operate before the fatal infarction occurs. The most likely explanation appears to be previous left ventricular disease, possibly vascular in origin or possibly related to some other aspect of diabetes. Attempts to improve survival among diabetic patients should be instituted before the onset of infarction.

\section{References}

1 Pell S, D'Alonzo CA. Factors associated with longterm survival of diabetics. $\mathcal{F} A M A$ 1970; 214: 1833-40.

2 Fuller JH, Shipley MJ, Rose G, Jarrett RJ, Keen H. Mortality from coronary heart disease and stroke in relation to degree of glycaemia: the Whitehall study. $\mathrm{Br}$ Med F 1983; 287: 867-70.

3 Garcia MJ, McNamara PM, Gordon T, Kannell WB. Morbidity and mortality in diabetics in the Framingham population: 16 year follow up study. Diabetes 1974; 23: 105-11.

4 Soler NG, Bennett MA, Lamb P, Pentecost BL, Fitzgerald MG, Malins JM. Coronary care for myocardial infarction in diabetics. Lancet 1974; i: 475-7. 
5 Opie LH, Tansey MJ, Kennelly BM. The heart in diabetes mellitus. Part II. Acute myocardial infarction and diabetes. S Afr Med f 1979; 56: 256-61.

6 Kibe' O, Nilsson NJ. Observations on the diagnostic and prognostic value and some enzyme tests. in myocardial infarction. Acta Med Scand 1967; 182: 597-610.

7 Sobel BE, Bresnahan GF, Shell WE, Yoder RD. Estimation of infarct size in man and its relation to prognosis. Circulation 1972; 46: 640-8.

8 Crall FV Jr, Roberts WC. The extramural and intramural coronary arteries in juvenile diabetes mellitus. Analysis of nine necropsy patients aged 19 to 38 years with onset of diabetes before age 15 years. Am $\mathfrak{f ~ M e d}$ 1978; 64: 221-30.

9 Fischer VW, Barner HB, Leskiw ML. Capillary basal laminar thickness in diabetic human myocardium. Diabetes 1979; 28: 713-9.

10 Vague P, Juhan I. Red cell deformability, platelet aggregation and insulin action. Diabetes 1983; 32 (suppl 2): 88-91.

11 McMillan DE. Plasma protein changes, blood viscosity and diabetic microangiopathy. Diabetes 1976; 25: 858-64.

12 Fuller JH, Keen H, Jarrett RJ, et al. Haemostatic variables associated with diabetes and its complications. $\mathrm{Br}$ Med F 1979; ii: 964-6.

13 Allison SP, Chamberlain MJ, Hinton P. Intravenous glucose tolerance, insulin, glucose and free fatty acid levels after myocardial infarction. $\mathrm{Br} \mathrm{Med} \mathcal{F} 1969$; 4: 776-8.

14 Liedtke AJ. Alterations of carbohydrate and lipid metabolism in the acutely ischemic heart. Prog Cardiovasc Dis 1981; 23: 321-36.

15 Opie LH, Tansey M, Kennelly BM. Proposed metabolic vicious circle in patients with large myocardial infarcts and high plasma free-fatty-acid concentrations. Lancet 1977; ii: 890-2.

16 Shell WE, Kjekshus JK, Sobel BE. Quantitative assessment of the extent of myocardial infarction in the conscious dog by means of analysis of serial changes in serum creatine phosphokinase activity. $\mathfrak{f}$ Clin Invest 1971; 50: 2614-25.

17 Norris RM, Whitlock RML, Barratt-Boyes C, Small $\mathrm{CW}$. Clinical measurement of myocardial infarct size. Modification of a method for the estimation of total cre- atine phosphokinase release after myocardial infarction. Circulation 1975; 51: 614-20.

18 Palmeri ST, Harrison DG, Cobb FR, et al. A QRS scoring system for assessing left ventricular function after myocardial infarction. $N$ Engl f Med 1982; 306: 4-9.

19 Gelman JS, Saltups A. Precordial ST segment depression in patients with inferior myocardial infarction: clinical implications. Br Heart $\mathcal{f}$ 1982; 48: 560-5.

20 Altman DG. Statistics and ethics in medical research. III. How large a sample? $B r$ Med f 1980; 281: 1336-8.

21 Killip T III, Kimball JT. Treatment of myocardial infarction in a coronary care unit. A two year experience with 250 patients. Am $\mathcal{f}$ Cardiol 1967; 20: 457-64.

22 Flint EJ, De Giovanni J, Cadigan PJ, Lamb P, Pentecost BL. Effect of GL enzyme (a highly purified form of hyaluronidase) on mortality after myocardial infarction. Lancet 1982; i: 871-4.

23 Cairns JA, Holder DA, Tanser P, Missirlis E. Intravenous hyaluronidase therapy for myocardial infarction in man: double-blind trial to assess infarct size limitation. Circulation 1982; 65: 764-71.

24 Husband DJ, Alberti KGMM, Julian DG. "Stress" hyperglycaemia during acute myocardial infarction: an indicator of pre-existing diabetes? Lancet 1983; ii: 179-81.

25 Oswald GA, Corcoran S, Yudkin JS. Prevalence and risks of hyperglycaemia and undiagnosed diabetes in patients with acute myocardial infarction. Lancet 1984; i: 1264-7.

26 Gwilt DJ. Why do diabetic patients die after myocardial infarction? Practical Diabetes 1984; 1: 36-9.

27 Nattrass M, Hale PJ. Clinical aspects of diabetic ketoacidosis. In: Nattrass M, Santiago JV, eds. Recent advances in diabetes. Edinburgh, London, Melbourne, New York: Churchill Livingstone, 1983: 231-8.

28 Jaffe AS, Spadaro JJ, Schechtman K, Roberts R, Geltman EM, Sobel BE. Increased congestive heart failure after myocardial infarction of modest extent in patients with diabetes mellitus. Am Heart $\mathcal{F}$ 1984; 108: 31-7.

29 Gwilt DJ, Petri M, Lamb P, Nattrass M, Pentecost $B L$. Effect of intravenous insulin infusion on mortality among diabetic patients after myocardial infarction. $\mathrm{Br}$ Heart $\mathcal{F}$ 1984; 51: 626-30. 